\title{
The morphology of the tongue musculature of the rock dove (Patagioenas livia) in relation to feeding habit
}

\author{
Fatma A. Al-Nefeiy $1^{1}$ and Bedoor A. Alahmary ${ }^{2}$ \\ ${ }^{1}$ Biology Department, Faculty of Science, King Abdulaziz University, Jeddah, Saudi Arabia \\ ${ }^{2}$ Biology Department, Faculty of Science, Taif University, Saudi Arabia
}

\begin{tabular}{|l|l|}
\hline Article history & Abstract \\
Received: 11 Feb, 2016 & In the present study, thirty adult specimens of the rock dove were examined for \\
Revised: $5 \mathrm{Mar}, 2016$ & studying the morphology of the tongue musculature. Morpho-functional analyses in \\
Accepted: $7 \mathrm{Mar}, 2016$ & $\begin{array}{l}\text { relation to food and feeding habit of the bird was studied. Results showed that the } \\
\text { lingual muscles of the rock dove are classified into four groups: 1. Gular muscles are } \\
\text { represented by Mylohyoideus, Serpihyoideus, Constrictor colli intermandibularis and } \\
\text { Constrictor colli cervicalis muscle. The Gular muscles of the rock dove occupy the } \\
\text { interman-dibular area and have no attachments on the hyoid skeleton. 2. Extrinsic } \\
\text { lingual muscles are represented by Branchiomandibularis, Genioglossus, Cerato- } \\
\text { hyoideus, Stylohyoideus, Cricohyoideus ventralis, and Cricohyoideus dorsalis. 3. } \\
\text { Intrinsic lingual muscles are represented by Cerato-glossus, Hypoglossus anterior and } \\
\text { Hypoglossus posterior. 4. Extrinsic laryngeal muscles are represented by } \\
\text { Tracheolateralis, Stern-otrachealis and Cleidotrachealis. } \\
\text { Keywords: Tongue; muscles; rock dove; feeding habit }\end{array}$ \\
\hline
\end{tabular}

\footnotetext{
To cite this article: Al-Nefeiy1 FA and BA Alahmary, 2015. The morphology of the tongue musculature of the
} rock dove (patagioenas livia) in relation to feeding habit. Res. Opin. Anim. Vet. Sci., 6(1): 32-39.

\section{Introduction}

The feeding mechanism is an important factor that determines the success of adaptation of vertebrates in their environment (Roth \&Wake, 1989). The tongue of birds is highly diverse organ showing a clear variation in its form shape and size. In birds, it cooperates with the jaw apparatus and the larynx in generating carefully coordinated movements during various behaviours, such as feeding and drinking (Erdogan and Alan, 2012). Morphological and functional studies of the avian species showed a close correlation the lingual form and anatomy with their feeding habits (Emura et al., 2009). Bhattacharyya (1980, 1985) described the functional morphology of jaw and tongue muscles of the common pigeon and some insect-eating birds. Shawki (1995) studied the structure and function of the lingual apparatus black kite. Bock (2001) studied the functional morphology of the Woodpecker feeding apparatus. Igwebuike and Eze (2010) designed study to provide basic data on the anatomy of the oropharynx and tongue of the African Pied crow. All these studies attempted to correlate the diversity of feeding adaptations with the structural modifications of the feeding apparatus of birds. The birds tongue shows various species-specific modifications in lingual muscles. Although some studies (Zweers, 1974, 1982; Zweers et al., 1977; Berkhoudt, 1985; Kooloos, 1986) have analyzed the synchronized interactions between the jaw and tongue during feeding and drinking in several avian species, studies on the morphology and histological structures of tongue conducted so far indicated a close correlation of the shape of the tongue with the method of food intake and the type of food and habitat of the birds (Parchami

*Corresponding author: Fatma A. Al-Nefeiy1, Biology Department, Faculty of Science, King Abdulaziz University, Jeddah, Saudi Arabia 
et al., 2010). So, the objective of our study, therefore, was to study and describe the muscles of the lingual apparatus of the rock dove in relation to feeding mechanism.

\section{Materials and Methods}

\section{Animals}

Thirty adult specimens of the rock dove were used in the present study. Birds were brought alive to the laboratory and then were killed by chloroform inhalation.

\section{Preparation of specimens for gross anatomy}

The head and neck were separated from the rest of the body, and then fixed in $10 \%$ formalin for $48 \mathrm{~h}$ according to the method of Calislar (1977). Then specimens were preserved in $3 \%$ phenoxy-ethanol during the time of dissection. A drop of 5\% iodine solution was added to the dissected muscles to stain them. Outline of each muscle was drawn with the help of binocular (Bock \& Shear, 1972). The figures were prepared by using the Camera Lucida (Roger Vaughan, England).

\section{Results}

The lingual muscles of the rock dove can be classified according to the anatomical and functional considerations into four group: Gular muscles, extrinsic lingual muscles, intrinsic lingual muscles and extrinsic laryngeal muscles.

\section{Gular muscles}

The Gular muscles of the rock dove occupy the intermandibular area and have no attachments on the hyoid skeleton. These muscles include Mylohyoideus, Serpihyoideus, Constrictor colli intermandibularis, and Constrictor colli cervicalis.

\section{Mylohyoideus muscle (Figs 1\&2)}

The mylohyoideus is a paired, sheet-like parallelfibered. It is slightly oblique posteriorly forming a posterior apex. This apex underlies the anterior part of the posteriorly located muscle serpihyoideus. Anteriorly, the muscle mylohyoideus underlies the entire glandula sublingualis. Each counterpart of the Mylohyoideus extends from its origin, which is an elongated line that lies on the dorso-medial side of the mandibular ramus to be inserted along the lateral border of the median raphe. This median raphe is attached anterioly on the antero-medial surface of the mandibular ramus and is extended posteriorly ending with muscle serpihyoideus. The muscle mylohoideus elevates the floor of the mouth resulting in the elevation of the tongue.

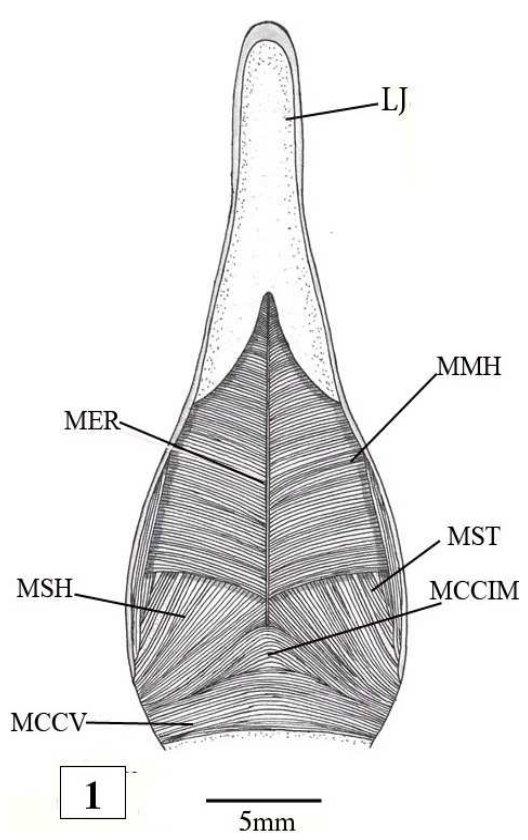

Fig. 1: Ventral view of the head and Gular region of rock dove, after the removal of the skin and the superficial fascia illustrating the serpihyoideus (MSH) muscle, stylohyoideus (MST) muscle and constrictor colli intermandibularis (MCCIM).

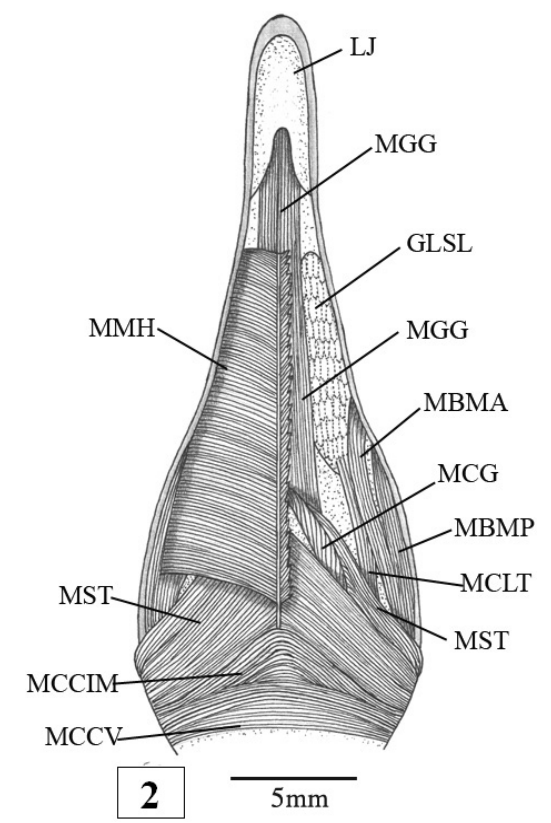

Fig. 2: Ventral view of the head and Gular region of rock dove, the muscle Branchiomandibularis anterior and posterior (MBMA \& MBMP), muscle Mylohyoideus (MMH) only partially removed on the left side to show Glandula sublingualis (GLSL), the muscle Genioglossus (MGG.), the muscle Ceratoglossus (MCG), and muscle Cleidotrachealis (MCLT). 


\section{Serpihyoideus muscle (Fig. 1\& 2)}

The muscle Serpihyoideus is a paired and fanshaped muscle with parallel fibres that lies posterior to the muscle mylohyoideus and anterior to muscle Constrictor colli intermandibularis. The muscle fibres of each counterpart converge from the posterior end of the mandibular ramus towards the middle of the posterior intermandibular space. The anterior border of the serpihyoideus is connected with the posterior one of the mylohyoideus through a connective tissue sheet of fascia. The posterior border of the Serpihyoideus is connected with the anterior one of the Constrictor colli intermandibularis thro-ugh the fusion of the epimysium of both the muscles. The Serpihyoideus arises from the retroarticular process of the mandibular ramus, rostarl to the origin of the Constrictor colli intermandibularis and caudal to the origin of the Stylohyoideus. The muscle rostro-medially is inserted on the posterior extension of the median raphe just behind the insertion of the mylohyoideus. The Serpihyoideus elevates the posterior portion of the buccal floor of the mouth and help in retracting the tongue.

\section{Muscle Constrictor colli intermandibularis (Fig. 1 \&} 2)

The Constrictor colli intermandibularis is unpaired, parallel-fibered with transversely oriented muscle fibres which extend between the muscle Serpihyoideus and the muscle Constrictor colli cervicallis. The Constrictor colli intermandibularis muscle spans the intermandibular space between the most posterior portion of the mandibular ramus. On the anterior side, the rostral border of the Constrictor colli intermandibularis muscle is connected to the caudal border of the Serpihyoideus muscle. Moreover, the epimysium covering the caudal border of that muscle is fused to the rostral surface of the Constrictor colli cervicallis muscle. The Constrictor colli intermandibularis muscle arises from the retroarticular process of the mandibular ramus, distal to the origin of the Serpihyoideus, and runs rostro-medially to be inserted on the median raphe. Constrictor colli intermandibularis elevates the posterior portion of the buccal floor of the mouth resulting in protracting the tongue and helping the passage of the food items from the buccal cavity to the oesophagus.

\section{Constrictor colli cervicalis (Fig. 1\&2)}

The Constrictor colli cervicalis is transversely arranged muscle fibres that encircle the neck. It is composed of irreGularly spaced muscle bundles. These bundles extend from the occipital region of the skull over the Dermotemporalis muscle to about anterior one-third of the neck, wrapping the ventral surface of the anterior portion of both the Sternotrachealis muscle and the Cleidotrachealis muscles. Laterally, the epimysium of the lateral surface of the Constrictor colli cervicalis muscle is connected to the skin of the neck, whereas the epimysium of the medial surface of it is tightly attached to the epimysium of the lateral surface of the Dermotemporalis muscle. The fusion between the two epimysiums acts as the site of the origin of the Constrictor colli cervicalis muscle. The Constrictor colli cervicalis muscle elevates the most posterior portion of the buccal floor of the mouth. Consequently, it helps the protraction of the tongue.

\section{Extrinsic lingual muscles}

The extrinsic lingual muscles of the rock dove include Branchiomandibularis, Genioglossus, Ceratohyoideus, Stylohyoideus, Cricohyoideus ventralis, and Cricohyoideus dorsalis.

\section{Branchiomandibularis (Fig. 2-6)}

The Branchiomandibularis is long, flat and compact muscle distinctly separated into two parts: Branchiomandibularis anterior muscle and Branchiomandibularis posterior muscle.

\section{Branchiomandibularis anterior muscle}

The Branchiomandibularis muscle is a paired, elongated and parallel-fiber which is rostrally thin, slender with parallel-fibers and ends semicircularly caudally. The muscle extends from the caudal two third of the mandibular ramus underpasses the Mylohyoideus muscle to the entire epibranchiale I, as well as the rostral one-third of epibranchiale II, passes over the Serpihyoideus muscle and Stylohyoideus muscle. The Branchiomandibularis anterior muscle runs straight from the medial surface of the mandibular ramus ventral to the anterior mandibular foramen. Then, it is curved caudally and becomes sub-cylindrically inserted into the entire Ceratobranchiale, and the ventro-lateral surface of the epibranchiale I as well as the proximal one-third of the cartilaginous epibranchiale II, enclosing the caudal portion of the origin of muscle Ceratoglossus and the entire origin of Ceratohyoideus muscle.

\section{Branchiomandibularis posterior muscle}

This muscle runs contiguously with Branchiomandibularis anterior muscle along its outer dorso-lateral aspect. The Branchiomandibularis posterior muscle extends along the ventral surface of the posterior half of the mandibuar ramus and the epibranchiale of the hyoid horn. The rostral portion of the muscle is slender parallel-fibres, while the posterior portion is enclosed dorso-laterally by the Branchiomandibularis anterior muscle. The Branchiomandibularis muscle arises fleshy from the ventromedial surface of the mandibular ramus, just posterior to the anterior mandibular foramen, and runs posteromedially adjacent to the Branchiomandibularis 


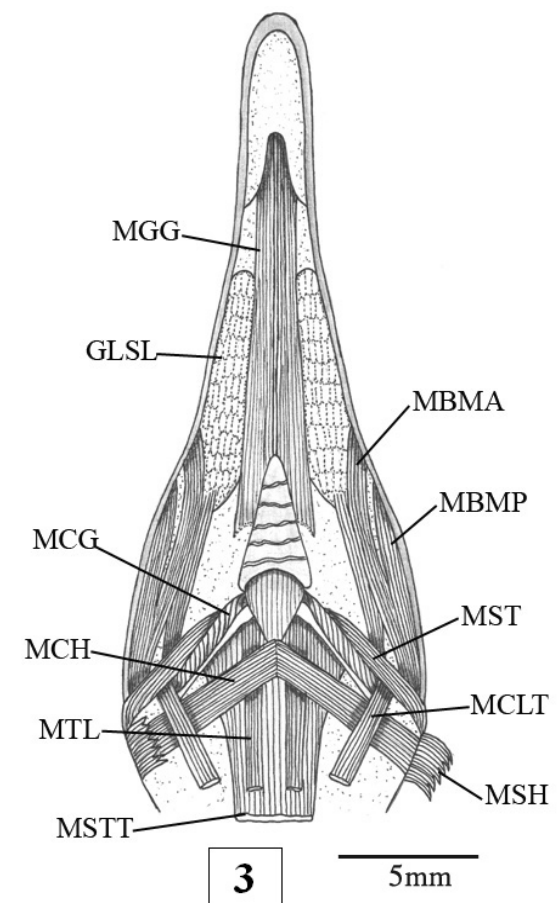

Fig. 3: Ventral view of the head and Gular region of rock dove, showing the muscle Genioglossus (MGG), and the deep muscles

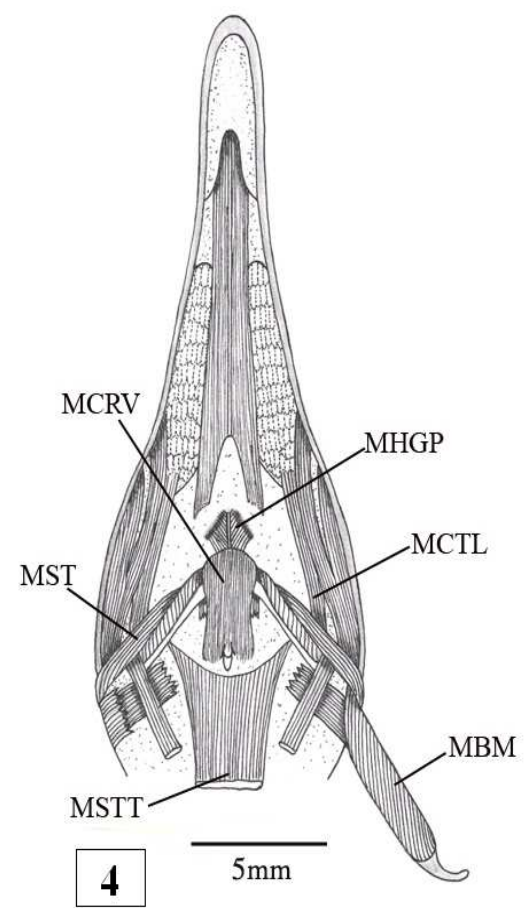

Fig. 4: Ventral view of the head and Gular region of rock dove, showing the muscle Genioglossus (MGG), muscle Cricohyoideus ventralis (MCRV), muscle Branchiomandibularis anterior and posterior (MBMA \& MBMP), and the deep muscles anterior muscle. Then, the two muscles fuse together forming a sheet-like muscle, which embraces the hyoid horn to be inserted on the posterior portion of the epibranchiale I. In addition, some fibres are inserted on the anterior portion of the epibranchiale II. Branchiomandibularis muscle represents the main protraction muscle of the tongue. Therefore, the muscle is antagonistic to the stylohyoideus muscle. Branchiomandibularis muscle affects the Articulatio epiceratobranchialis yielding to the abduction of the paired hyoid horns.

\section{Genioglossus muscle (Fig. 2-4)}

The Genioglossus muscle is an unpaired, ribbonlike and parallel-fibered muscle. It extends rostromedially on the ventral buccal floor from the mandibular symphysis to the hyoid skeleton caudally. This muscle is located dorsal to the anterior portion of the muscle Mylohyoideus. During the posterior extension of the Genioglossus muscle and before reaching the hyoid skeleton, the pair collateral parts diverge laterally and lost their medial connection. The epimysium of that muscle is connected laterally with the glandular capsule of the paired gland sublingual. The Genioglossus muscle arises fleshy from the inner surface of the mandibular symphysis, then, it runs caudally to be inserted fleshy on the folds at the site of connection of the free portion of the tongue with the floor of the mouth. The muscle Genioglossus assists in protraction of the tongue.

\section{Ceratohyoideus muscle (Fig. 3-8)}

Ceratohyoideus muscle is a paired, fan-shaped and parallel-fibered muscle. It lies dorsal to the muscle Serpihyoideus. The muscle Ceratohyoideus extends from its origin that lies on the dorsal surface of the distal end of the Os ceratobranchiale just anterior to the Articulatio epi-ceratobranchialis, then the muscle fan out towards its insertion that lies on the dorsal surface of the posterior extension of the median raphe.

Ceratohyoideus affects the Articulatio epiceratobranchialis yielding to the adduction of the paired hyoid horn resulting in the elevation of the laryngeal mound and the retraction of the tongue. Thus, the Ceratohyoideus is antagonistic to the Branchiomandibularis muscle.

\section{Stylohyoideus muscle (Fig. 1-7)}

The Stylohyoideus is a paired, ribbon-like and parallel-fibered muscle. It extends from the outer caudo-lateral margin of the retroarticular process of the mandible to the ventro-lateral surface of the Basihyale. Along the extension of that muscle, it underpasses posterior to the Serpihyoideus muscle and Branchioman-dibularis muscle and crosses the ceratoglossus muscle anteriorly. The Stylohyoideus 


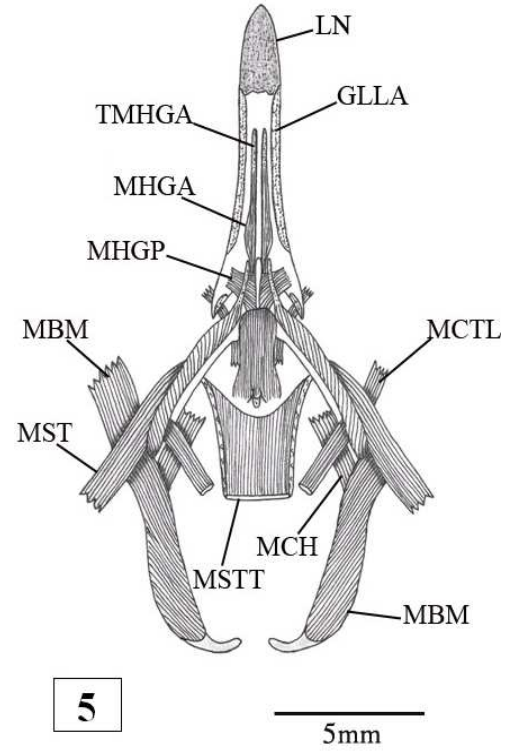

Fig. 5: Ventral view of the tongue of rock dove, after isolation from the mandible and head, showing anterior free portion of the tongue with the Lingual nail ( $L N)$, Glandula lingualis anterior and posterior (GLLA \& GLLP), and illustrating the muscle Ceratoglossus (MCG), as well as, the relations between the deep lingual muscles

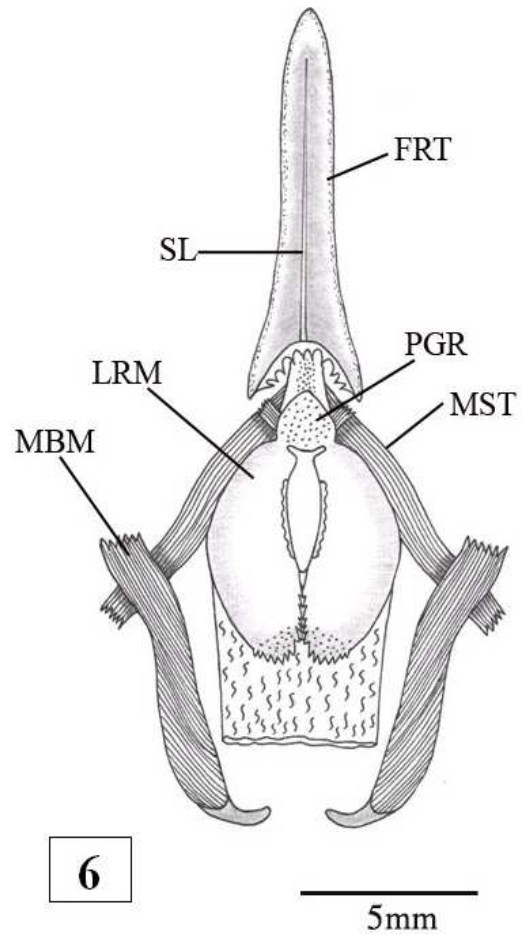

Fig. 6: Dorsal view of the tongue, Larynx, and hyoid horns of rock dove, showing the free portion of the tongue (FRT), preglottal region (PGR), Laryngeal mound (LRM), laryngeal wing (LRW), lingual wing (LW) and lingual papillae (LP) muscle arises fleshy and flatly from the outer dorsolateral surface of the retroarticular process of the mandibular ramus lateral to the site of origin of the serpihyoideus muscle. Then it runs anteriorly to be inserted broadly and fleshy on the ventro-lateral surface of the Basihyale. The contraction of the Stylohyoideus muscle yields to the retraction of the tongue. Thus, the muscle Stylohyoideus is antagonistic to the muscle branchioman-dibularis.

\section{Cricohyoideus ventralis muscle (Fig. $4 \& 8$ )}

Cricohyoideus ventralis is a paired and parallelfibered muscle which covers the ventral surface of the cricoid cartilage. The ventro-lateral surface of the muscle is covered by tracheolateralis muscle. Cricohyoideus ventralis muscle extends straight from its ventral to the caudal part of the Basihyale and turns dorso-laterally to runs lateral to the urohyale. Then the muscle fibres fan out dorso-laterally to be inserts on the cricoids. The muscle cricohyoideus ventralis cooperates in retraction of the tongue.

\section{Cricohyoideus dorsalis muscle (Fig. 7)}

Cricohyoideus dorsalis muscle is a paired and parallel-fibered muscle which lies dorso-medial to the Stylohyoideus muscle and lateral to the dilator glottides muscle. Each counterpart of Cricohyoideus dorsalis muscle extends from its origin that lies on the lateral surface and the antero-ventral surface of the cricoid cartilage to be inserted on the dorso-lateral surface of the distal end of Os basihyale, just dorsal to the insertion site of Stylohyoideus muscle and proximal end of the Os ceratobranchiale. Meanwhile, few fibres are inserted on the dorsal surface of the articular ligament of the Articulatio cerato-basihyalis.

The Cricohyoideus dorsalis muscle retracts the tongue by pulling the Basihyale and Ceratobranchiale backwards. It is synergistic with Stylohyoideus muscle and other extrinsic laryngeal muscle. Meanwhile, it affects the Articulatio cerato-basihyalis yielding to the adduction of the paired hyoid horn. Thus, it is synergistic with the muscle Ceratohyoideus.

\section{Intrinsic lingual muscle}

The intrinsic lingual muscles of the rock dove have the origin and the insertion on the elements of the hyoid skeleton. Three muscles included in this group are Ceratoglossus, hypoglossus anterior muscle and Hypoglossus posterior.

\section{Muscle Ceratoglossus (Fig. 2-4)}

Ceratoglossus muscle is a paired and spindleshaped which envelops the distal two-thirds of the Os ceratobranchiale, and then the muscle becomes tendinous at the level of the Artculatio ceratobasihyalis. A tendon runs anteriorly towards the Os 
paraglossale and flanks the Articulatio ceratobasihyalis. So Ceratoglossus passes on two articulations within the hyoid skeleton; the Articulatio paraglossobasihyalis and the Articulatio cerato-basihyali. The muscle Ceratoglossus arises from the dorso-lateral surface of the Os ceratobranchiale to be inserted by its elongated tendon on the ventro-lateral surface of the Os paraglossale. Ceratoglossus muscle affects two joints within the hyoid skeleton; the articulatio paraglossobasihyalis yielding to the flexion of the Os paraglossale resulting in the depression of the free portion of the tongue. Meanwhile, the muscle ceratoglossus affects the paired Articulatio cerato-basihyalis yielding to the abduction of the paired hyoid horns.

\section{Hypoglossus anterior muscle (Fig. 5\&8)}

The muscle hypoglossus anterior is a paired and spindle-shaped muscle that extends along the ventral surface of the Os paraglossal (PG). It runs anteriorly along the ventral surface of the Os paraglossale. The muscle is differentiated into two parts; a caudal fleshy part and a tendinous rostral one. That muscle arises fleshy from the caudal margin of the ventral surface of the Os paraglossale lateral to the basihyale-paraglossale articulation. Then the muscle extends rostrally and becomes narrow represented by a long, flat and stiff tendon that arises from the base of the lingual nail to be inserted on the most rostral tip of the Os paraglossale. The hypoglossus anterior muscle affects the Os paraglossale. Therefore, the full contraction of this muscle bends the Os paraglossale ventrally. Consequently, full contraction produces a ventral bending of the tip of the free portion of the tongue. Meanwhile, the partial contraction of the muscle causes a ventral bending of the lingual nail which means the bending of the anterior tip of the tongue.

\section{Hypoglossus posterior Muscle (Fig. 4, 5,7\& 8)}

Hypoglossus posterior muscle is a paired, short sheet-like and parallel-fibered muscle. It extends between the posterior paraglossale and the bony part of the Os basihyale. Hypoglossus posterior arises fleshy, from the ventral surface of the posterior paraglossalis, to be inserted fleshy on the ventral surface of the Os basihyale, lateral to the Crista ventralis basihyalis, and anterior to the Articulatio cerato-basihyalis.

The contraction of Hypoglossus posterior muscle affects the Articulatio paraglosso-basihyalis yielding to the elevation of the Os paraglossale resulting in the elevation of the free portion of the tongue.

\section{Extrinsic laryngeal muscles}

The extrinsic laryngeal muscle of the rock dove, consists of three muscles; muscle Tracheolateralis, muscle Sternotrachealis, and muscle Cleidotrachealis.

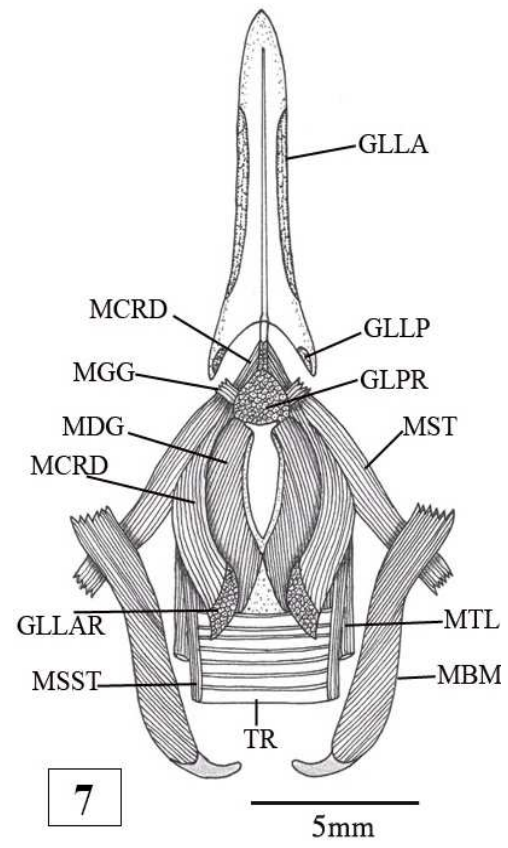

Fig. 7: Dorsal view of the tongue of rock dove, the laryngeal wing removed to expose the origin site of the muscle cricohyoideus dorsalis (MCRD). In addition, the Glandula Preglottalis (GLPR), Glandula Laryngeal (GLLAR), and muscle dilator glottidis (MDG).

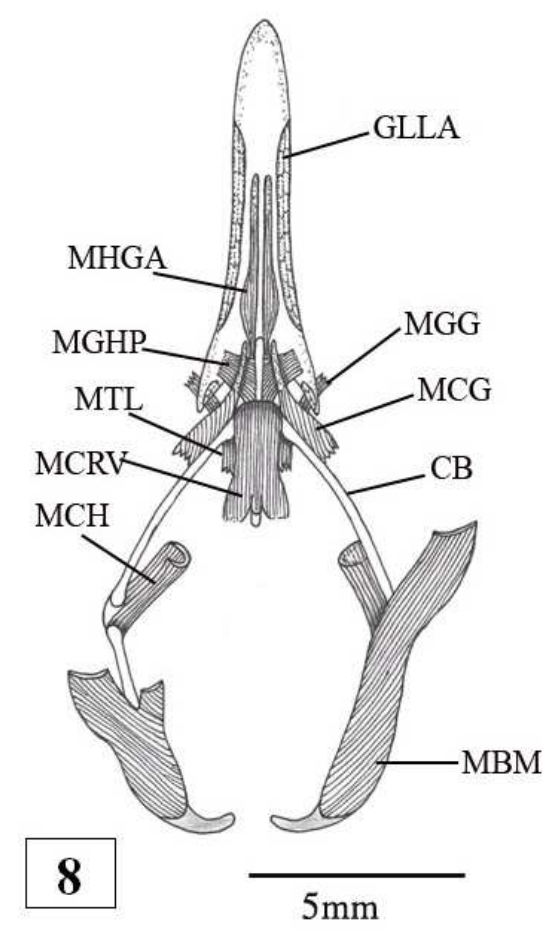

Fig. 8: Ventral view of the tongue of rock dove, showing the extrinsic, intrin-sic lingual muscles, as well as, the lingual salivary gland. 


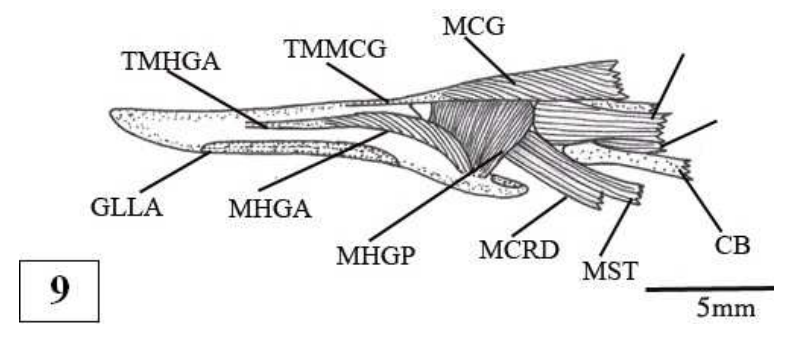

Fig. 9: Lateral view of the anterior portion of the tongue of rock dove, showing the tendon of muscle Hypoglossus anterior (TMHGA), and tendon of muscle Ceratoglossus (TMCG). In addition, the muscle Hypoglossus anterior and posterior (MHGA \& MHGP), muscle Stylohyoideus (MST), muscle Cricohyoideus dorsalis and ventralis (MCRD \& MCRV), and muscle Tracheolateralis (MTL), as well as, the lingual salivary gland

\section{Tracheolateralis muscle (Fig. 3)}

The muscle Tracheolateralis is a paired, elongated, ribbon-like and parallel-fibered muscle that lies lateral to the muscle Sternotrachealis. Usually, their fibres are combined with the muscle Sternotrachealis. The muscle Tracheolateralis extends from the syrinx along the entire length of the cervical region to be inserted on the lateral surface of Basihyale. The muscle Tracheolateralis retracts the larynx.

\section{Sternotrachealis muscle (Fig. 3, 4 \& 5)}

The muscle Sternotrachealis is an unpaired, elongated, sheet-like and parallel-fibered. The muscle sternotrachealis extends anteriorly from the rostromedial surface of the sternum along the entire length of the cervical region to be inserted on the ventral surface of the posterior edge of the cricoid cartilage. The insertion site of the muscle Sternotrachealis lies posterior to the origin site of the muscle Cricohyoideus ventralis. The ventral surface of the posterior portion of the muscle Sternotr-achialis overlies the muscle Cleidotrchialis and the muscle Constrictor colli cervicalis.

The muscle Sternotrachealis retracts the larynx. Thus, it is synergistic with the muscle Stylohyoideus.

\section{Cleidotrachealis muscle (Fig. 3\&4)}

Cleidotrachealis muscle is a paired, elongated and parallel-fibered muscle which lies lateral to the muscle tracheolateralis and adheres to the skin of the cervical region. Laterally, the epimysium of the collateral parts of the muscle is connected with the glandular capsule of the paired glandula sublingualis. Cleidotrachealis retracts the larynx. Consequently it helps the retraction of the tongue. Thus, it is synergistic with the muscle Stylohyoideus.

\section{Discussion}

Birds are adapted to different environments with their food and feeding habits. There is a correlation between the structure of the lingual apparatus of the bird and its food. Morphological structure of the tongue of bird species may be directly associated with food type consumed and feeding habit of the bird (Campbell \& Lack 198; Parchami et al., 2010). Many authors revealed that the lingual apparatus differ according to the type of food and method of food intake (Homberger, 1986; Shawki \& Al-Jalaud, 1994; Shawki, 1995; Shawki \& Abdel-Rahmaan, 1998; Parchami et al., 2010). Tongue plays an important role in manipulating and swallowing food items. The main food of the rock dove is seeds which are hard. This type of food needs well developed muscles to elevate, depress, protract and retract the tongue during feeding. The present work revealed that Mylohyoideus, Serpihyoideus, Constrictor colli intermandibularis and Constrictor colli cervicalis elevate the floor of the mouth resulting in the elevation and retraction of the tongue, then helping the passage of the food items from the buccal cavity to the oesophagus. Muscle Branchiomandibularis is well developed and it is responsible with the other extrinsic lingual muscles for protraction and retraction of the tongue during feeding as well as adduction of the paired hyoid horn. This is in accordance with Korzun et al. (2008) in pigeons and sand grouse. Igwebuike and Anagor (2013) demonstrated that the oropharynx and tongue of the Muscovy duck exhibit certain anatomical features and the morphological modifications of this region of the digestive tract may be adaptations to the bird's habitat and mode of feeding. Muscle Ceratoglossus acts as abduction of the paired hyoid horns, thus its function is antagonistic to the extrinsic lingual muscle. Elevation and depression of the free portion of the tongue are done by Hypoglossus anterior and Hypoglossus posterior muscles. These results are in agreements with Shawki \& Abdel-Rahmaan (1998) who stated that intrinsic lingual muscles of the cattle egret. Extrinsic laryngeal muscles play an important role during swallowing of food, they retract the larynx to help moving the food from the buccal cavity to the oesophagus. The free portion of the tongue (the paraglossale) is composed of hyaline cartilage which gives its flexibility for rotation and bending during feeding (Zweer, 1982). Shawki \& Al-Jalaud (1994) suggested that mechanism of feeding of Larus argentatus which is fish eater bird depending on the anatomical features of the tongue especially the lingual muscles. While, Zweers (1982) suggested two different mechanisms in Columba livia, slide and glue for eating small grains and catch and throw for eating large ones by using cinematography. The above results showed a 
wide range of the anatomical and functional variability in the tongue musculature of the rock dove in comparison with different studied species.

\section{Acknowledgement}

We would like to thank Deanship of Scientific Research (DSR), King Abdulaziz University, Jeddah, for their kind help and providing the necessary facilities for the preparation of the paper. This work would not have been possible without the generous assistance of DSR.

\section{References}

Berkhoudt H (1985) Structure and function of avian taste receptors. In: Form and Function in Birds. Vol. 3. (King AS, McLelland J, eds). Academic Press, London.

Bhattacharyya BN (1980) The morphology of the jaw and tongue musculature of the common pigeon, Columba livia, in relation to its feeding habit. Proc Zool Soc Calcutta 31: 95-127.

Bhattachryya B N (1985) Functional morphology of the tongue muscles of Indian insect-eating birds. Gegenbaurs Morphol Jahrb 131: 93-123.

Bock WJ (2001) Functional morphology of the woodpecker feeding apparatus. In: Dutta HM, Datta Munshi JS, (eds.). Vertebrate functional morphology. Horizon of Research in the $21^{\text {st }}$ century. pp: 295-313.

Bock WJ, Shear CR (1972) A staining method for gross dissection of vertebrate muscles. Anat Anz 130: 222-227.

Campbell B, Lack E (1985) A Dictionary of Birds. Calton T AD. Poyser.

Calislar T (1977) Tavuk diseksiyonu Ankara Univ Basimevi, Ankara, Turkey. Pp: 28-31.

Emura S, Okumura T, Chen H (2009) Scanning electron microscopic study of the tongue in the Japanese pygmy woodpecker (Dendrocopes kizuki). Okajimas Folia Anat Jpn 86: 31-35. 20.

Erdogan S, Alan A (2012) Gross anatomical and scanning electron microscopic studies of the oropharyngeal cavity in the European magpie (Pica pica) and the common raven (Corvus corax). Microsc Res Tech 75: 379-389

Homberger DG (1986) The lingual apparatus of the African grey parrot Psittacus erithacus Linn. (Aves, Psittacidae): Description and theoretical mechanical analysis. American Ornithologists Union (AOU) 39: 1-233.

Igwebuike UM, Eze UU (2010) Anatomy of the oropharynx and tongue of the African pied crow (Corvus albus ). Vet arhiv 80: 523-531.

Igwebuike UM, Anagor, TA, (2013) The morphology of the oropharynx and tongue of the muscovy duck (Cairina moschata). Vet Arh 83 (6): 685-693.

Korzun LP, Erad C, Gasc JP, Dzerzhinsky FJ (2008) Bill and hyoid apparatus of pigeons (Columbidae) and sandgrouse (Pteroclididae): a common adaptation to vegetarian feeding? CR Biol 331: 64-87.

Kooloos, JGM (1986) A conveyer belt model for pecking in the mallard, Anas platyrhynchos L., Neth J Zool 36: 47-87.

Parchami A, Fatahian Dehkordi RA, Bahadoran S (2010) Scanning electron microscopy of the tongue in the golden eagle Aquila chrysaetos (Aves: Falconiformes: Accipitridae). J Zool 5: 257263.

Roth G, Wake DB (1989) Conservatism and innovation in the evolution of feeding in vertebrates. In: Complex organismal functions, integration and evolution in vertebrates. John Wiley \&Sons, New York, pp: 7-21.

Shawki NA (1995) A correlation between the functional morphology of the lingual apparatus and feeding behavior of the Egyptian black kite, Milvus migrans aegyptius. Egypt J Anat 18: 179-209.

Shawki NA, Abd El-Rahmaan GH (1998) The functional morphology of the lingual apparatus of the cattle egret, Bubulcus ibis, (Aves.). J Union Arab Bio 9: 22-38.

Shawki NA, Al-Jalaud NA (1994) Structrue and function of the lingual apparatus of the collared dove, Sterptopelia decaocto, Egypt. J Anat 17: 5178.

Zweers GA (1974) Structure, movement and myography of the feeding apparatus of the mallard, Anas platyrhynchos L., Neth. J Zool 24: 323-467.

Zweers GA (1982) The feeding system of the pigeons, Columba livia L. Adv Anat Embryol Cell Bio 73: 1-108.

Zweers GA, Gerritsen AFC, Kranenburg-Voogd PJ van (1977) Mechanics of feeding of the mallard (Anas platyrhynchos L., Aves, Anseriformes). In: Hecht MK., Szalay FS. (eds.). Contributions to Vertebrate Evolution.3: 109. Karger, Basel. 